\title{
The mediating role of dichotomous thinking and emotional eating in the relationship between depression and BMI
}

Citation for published version (APA):

Antoniou, E. E., Bongers, P., \& Jansen, A. (2017). The mediating role of dichotomous thinking and emotional eating in the relationship between depression and BMI. Eating Behaviors, 26, 55-60. https://doi.org/10.1016/j.eatbeh.2017.01.007

Document status and date:

Published: 01/08/2017

DOI:

10.1016/j.eatbeh.2017.01.007

Document Version:

Publisher's PDF, also known as Version of record

\section{Document license:}

Taverne

Please check the document version of this publication:

- A submitted manuscript is the version of the article upon submission and before peer-review. There can be important differences between the submitted version and the official published version of record.

People interested in the research are advised to contact the author for the final version of the publication, or visit the DOI to the publisher's website.

- The final author version and the galley proof are versions of the publication after peer review.

- The final published version features the final layout of the paper including the volume, issue and page numbers.

Link to publication

\footnotetext{
General rights rights.

- You may freely distribute the URL identifying the publication in the public portal. please follow below link for the End User Agreement:

www.umlib.nl/taverne-license

Take down policy

If you believe that this document breaches copyright please contact us at:

repository@maastrichtuniversity.nl

providing details and we will investigate your claim.
}

Copyright and moral rights for the publications made accessible in the public portal are retained by the authors and/or other copyright owners and it is a condition of accessing publications that users recognise and abide by the legal requirements associated with these

- Users may download and print one copy of any publication from the public portal for the purpose of private study or research.

- You may not further distribute the material or use it for any profit-making activity or commercial gain

If the publication is distributed under the terms of Article $25 \mathrm{fa}$ of the Dutch Copyright Act, indicated by the "Taverne" license above, 


\title{
The mediating role of dichotomous thinking and emotional eating in the relationship between depression and BMI
}

\author{
Evangelia E Antoniou* * Peggy Bongers, Anita Jansen \\ Maastricht University, Faculty of Psychology and Neuroscience, Department of Clinical Psychological Science, The Netherlands
}

\section{A R T I C L E I N F O}

\section{Article history:}

Received 5 August 2016

Received in revised form 22 December 2016

Accepted 16 January 2017

Available online 17 January 2017

\section{Keywords:}

Depression

BMI

Dichotomous thinking

Emotional eating

Mediation

\begin{abstract}
A B S T R A C T
Obesity and depression have important health implications. Although there is knowledge about the moderators of the depression-obesity association, our understanding of the potential behavioral and cognitive mediators that may explain the relationship between depression and obesity, is scarcely researched. The aim of this study is to investigate the mediating role of emotional eating and dichotomous thinking in the depression-obesity relationship.

Data on 205 individuals from a community-based study conducted at Maastricht University, Netherlands were used. Self-reported data on depression, emotional eating and dichotomous thinking were collected and BMI scores were calculated in a cross-sectional research design.

Correlations between variables were calculated. The primary analysis tested the hypothesis that depression has an effect on BMI through dichotomous thinking and emotional eating. A two-mediator model was used to predict the direct and indirect effects of emotional eating and dichotomous thinking on the depression-BMI relationship.

Depression was positively correlated with BMI $(r=0.21, p=0.005)$, emotional eating $(r=0.38, p<0.001)$ and dichotomous thinking $(\mathrm{r}=0.49, \mathrm{p}<0.001)$. Dichotomous thinking and emotional eating were positively correlated with BMI $(r=0.35, p<0.001$; and $r=0.45, p<0.001$ respectively). Both dichotomous thinking $(Z=2.54$, $p=0.01,95 \%$ confidence intervals $=0.01-0.17)$ and emotional eating $(Z=3.92 p<0.001,95 \%$ confidence intervals $=0.06-0.19$ ) could explain the depression-BMI relationship.

The assessment of emotional eating and dichotomous thinking might be useful in guiding assessment and treatment protocols for weight management.

The present study adds to the existing literature on the role of dysfunctional cognitions and emotions on eating behavior, and particularly to the factors that may impede people's ability to control their eating.
\end{abstract}

(c) 2017 Elsevier Ltd. All rights reserved.

\section{Introduction}

Obesity and depression are problems with important public health implications (Mathers \& Loncar, 2006; Murray \& Lopez, 1997; von Ruesten et al., 2011). Obesity is a major risk factor for cardiovascular disease, diabetes, and cancer (Organization, 2013). The 2011 World Mental Health Survey, including data from 17 countries, found that approximately 1 in 20 people report experiencing a depressive episode (Marcus, M., Van Ommeren, Chisholm, \& Saxena, 2012). Depressive symptoms can cause considerable impairments in an individual's ability to handle daily responsibilities (Marcus et al., 2012). In this respect, both depression and obesity can increase the burden of disease with enormous economic costs (Marcus et al., 2012; Organization, 2013).

\footnotetext{
* Corresponding author at: Department of Clinical Psychological Science, Faculty of Psychology and Neuroscience, Maastricht University, P.O. Box 616, 6200 MD, The Netherlands.

E-mail address: eva.antoniou@maastrichtuniversity.nl (E.E. Antoniou).
}

Studies (Carpenter, Hasin, Allison, \& Faith, 2000; McElroy et al., 2004) have shown that people with obesity are more likely to experience a mood disorder, like depression compared to those who are not obese. A meta-analysis of 17 community-based cross-sectional studies among adults, showed a positive overall association between depression and obesity (de Wit et al., 2010) suggesting that depression is associated with an $18 \%$ increased risk of becoming obese.

Potential moderating factors of the association between depression and obesity include being female (Heo, Pietrobelli, Fontaine, Sirey, \& Faith, 2006) (Scott, McGee, Wells, \& Oakley Browne, 2008), having higher education (Ross, 1994) and being younger (Blaine, 2008; Heo et al., 2006). Although there is knowledge about the moderating factors in the depression-obesity relationship, our understanding of the potential mediators that could explain how the relationship between depression and obesity forms, is scarcely researched.

It is evident that depression and obesity are diseases of current scientific interest which are not caused by single factors, but by complex patterns of risk factors. Identifying such mechanisms, which may vary 
in different subgroups and populations, requires determination of how these patterns of risk factors may "work together" (Kraemer, Stice, Kazdin, Offord, \& Kupfer, 2001). Investigating the mediating factors of the depression-obesity relationship, can lead to the design of interventions in order to discontinue those mechanisms responsible for this relationship.

In their theoretical review of the depression-obesity association, Markowitz and colleagues (Markowitz, Friedman, \& Arent, 2008) suggest that behavioral and cognitive mechanisms may mediate the depression-obesity relationship. In this study, we will focus on emotional eating and dichotomous thinking as potential behavioral and cognitive mechanisms which could shed some light on why depression and body weight are related.

Disturbances in eating behavior are common in both depression and obesity, and eating to alleviate negative affect may be one pathway to obesity in depressed individuals. Negative emotions, such as depression, are one of the most proximate psychological factors related to disordered eating. In an attempt to identify why some individuals eat more than others while suffering depressive symptoms, a main disordered eating style has been identified. Some individuals, who struggle with their weight, engage in a maladaptive eating behavior termed emotional eating (Geliebter \& Aversa, 2003a). An aspect of emotional eating refers to the tendency to eat in response to aversive negative states (Alberts, Thewissen, \& Raes, 2012) and has been related to both obesity (Geliebter \& Aversa, 2003b; Ozier et al., 2008) and depressive symptoms (Owens, v. S., \& van Leeuwe, 2009).

Previous research suggests that individuals with depressive symptoms also show evidence of "depressogenic schematic processing" which includes patterns of negative and "all-or-none thinking" (Teasdale et al., 2001). The individual's tendency to think in terms of binary opposition, such as "black or white", and "good or bad", is a cognitive process termed dichotomous thinking. Dichotomous thinking has recently been found to be involved in eating disorders (Fairburn, Cooper, \& Shafran, 2003) as well as in obesity. A study by Dove, Byrne, and Bruce (2009) showed that dichotomous thinking moderated the association between depression and obesity in weight loss treatment seeking obese and overweight individuals. Those with a dichotomous thinking style tended to have similar levels of depression, regardless of whether they were obese or overweight. This suggests that any irregularity from what a dichotomous thinker considers an "acceptable" body weight may increase their risk for depression.

Eating disordered individuals with dichotomous thinking styles also tend to think of food as "good or bad", themselves as being "on" or "off" a diet and their weight as "acceptable" or "totally unacceptable" (Williamson, White, York-Crowe, \& Stewart, 2004). Rigid dietary rules and all-or-nothing cognitions (i.e., I have blown my diet after eating one piece of "forbidden food") are generally present in individuals with weight and eating concerns.

The existing evidence suggests that depressive symptoms are related to obesity, although the evidence is mainly focused on clinically depressed individuals. A few studies in community samples, suggest that increased levels of depression are associated with obesity (Baumeister \& Harter, 2007; Herva et al., 2006).

Emotional eating is associated with depression (Owens et al., 2009) and obesity (Ozier et al., 2008). Only two studies (Kontinnen, Silverntoinen, Sarlio-Lahteenkorva, Mannisto, \& Haukkala, 2010) have researched the role of emotional eating as a mediator in the relationship between depression and several adiposity indicators, including BMI or weight gain (T. van Strien, Konttinen, Homberg, Engels, \& Winkens, 2016). These studies have examined the role of emotional eating as a mediator in the relationship between depression and obesity without looking at dichotomous thinking style. With this study we aim to examine in one model the direct and indirect effects of these two mediators.

The only available evidence on the association between dichotomous thinking and BMI comes from clinical settings with obese people with diagnosed eating disorders investigating primarily weight loss as an outcome (Dove et al., 2009; Lethbridge, Watson, Egan, Street, \& Nathan, 2011) or having used a pre-treatment sample (Dove et al., 2009). Pre-treatment samples are not really representative of the general population.

The aim of this study is to investigate the association between depression and BMI in a non-treatment sample motivated to lose weight. Based on previous research findings, it is hypothesized that depression will be positively associated with obesity and that emotional eating and dichotomous thinking will mediate this relationship. Beck's cognitive-behavioral theory (Beck, 2008) highlights the role of thoughts and negative mood in depression. Further, we hypothesize that depressive thoughts may influence emotional eating leading to overweight or obesity. The model we will employ to investigate the total and specific effect of each of the two mediators is schematically presented in Fig. 1.

\section{Methods}

\subsection{Subjects}

Data for this cross-sectional study were used from a volunteer population-based study conducted at Maastricht University, Netherlands. The study collected panel data on physiologic and psychological traits of overweight, obese and normal weight people between 19 and 58 years old, followed through time at intervals of six months. Data are collected since January 2012. Overweight/obese participants were selected to participate in the study if their body weight index was above 27. All participants were recruited via local advertisements of the study and via posts in the social media (Facebook and internet account of the study). Pregnant and breastfeeding women were excluded from the study, as well as people using corticosteroids or those with thyroid gland diseases. In addition, people were excluded if they were undergoing psychological or medical treatments for eating or other disorders at the time of the study. For the purposes of this study we used data from the baseline measurements collected between January 2012 and January 2015. A total of 205 individuals were included in the analyses. Of those, 60 were classified as normal weight $(18.5<\mathrm{BMI}<24.9 \mathrm{~kg}), 40$ as overweight $(27<\mathrm{BMI}<29.9 \mathrm{~kg})$ and 105 as obese (BMI $\geq 30 \mathrm{~kg}$ ). All participants consented before participation and the study was approved by the Ethics Committee Psychology of Maastricht University.

\subsection{Materials}

\subsubsection{BMI}

BMI was determined following measurement of height and weight, with the participants in light clothing and no shoes. Weight was measured using an appropriate medical scale and standing height was

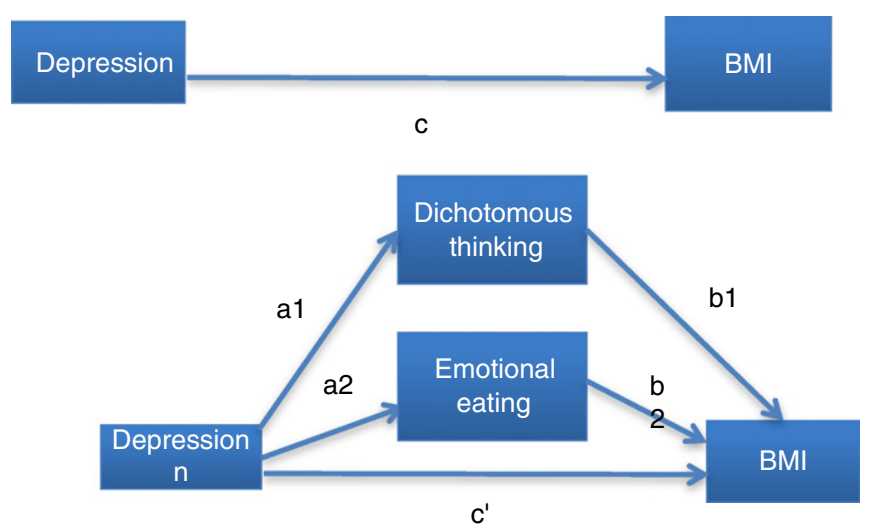

Fig. 1. Illustration of a two-mediator design. (A) Depression affects BMI. (B) Depression is hypothesized to exert indirect effects on BMI through dichotomous thinking $\left(\mathrm{M}_{1}\right)$ and emotional eating $\left(\mathrm{M}_{2}\right)$ 
measured to the nearest $0.1 \mathrm{~cm}$. BMI was calculated by dividing the weight in kilograms by the height in metres squared $\left(\left(\mathrm{kg} /\right.\right.$ height $\left.\left(\mathrm{m}^{2}\right)\right)$ and was classified according to the WHO standard guidelines as: normal weight (18.5-24.9 kg), overweight (27-29.9 kg) and obese ( $\geq 30 \mathrm{~kg})$.

\subsubsection{Depression}

Symptoms of depression were assessed by the Beck Depression Inventory-version II (BDI-II) (Beck, 2008). BDI-II consists of 21 groups of 4 statements (i.e., 'I'm sad all the time'). Participants select the one statement from each group that best describes the way they have been feeling the past two weeks. Each statement corresponds to a severity rating from 0 (minimal) to 3 (severe). The BDI-II score is the sum of the 21 severity ratings (ranging from 0 to 63). Higher scores indicate more severe depressive symptoms. The Cronbach's alpha for this scale was 0.91 .

\subsubsection{Dichotomous thinking}

The Dichotomous Thinking in Eating Disorders Scale (DTEDS) (Byrne, Allen, Dove, Watt, \& Nathan, 2008) was used to assess the extent to which participants showed a 'black and white' cognitive thinking style. The DTEDS contains two subscales, the eating subscale which measures dichotomous thinking related to eating, dieting, and weight, and the general subscale which measures dichotomous thinking more broadly. Items include "I think of things in 'black and white' terms", and "I think of myself as doing things either very well or very badly". A total score is calculated as the average of all items. Scores range from 1 to 4 and higher scores indicate higher dichotomous thinking. The DTEDS has good test-retest reliability and internal consistency and is suitable for use with clinical and non-clinical samples (Byrne et al., 2008). The Cronbach's alpha for this scale was 0.88 .

\subsubsection{Emotional eating}

Emotional eating was assessed using the Dutch Eating Behavior Questionnaire (DEBQ) (van Strien, Frijters, Bergers, \& Defares, 1986). It comprises 33 items responding to a Likert-type scale ranging from $1=$ seldom to $5=$ very often, corresponding to three scales (emotional eating, external eating and restraint). For the purposes of this study we only used the emotional eating scale. The Emotional eating scale contains 13 items (i.e., Do you have the desire to eat when you are irritated?). Higher scores indicate increased emotional eating. The Cronbach's alpha for this scale was 0.93 .

\subsubsection{Control variables}

Age and education were used as control variables in the mediation analysis models. The two variables were selected because they were highly correlated with depression and based on previous literature were expected to be associated with increased BMI.

Age was included as a continuous variable while education was used as a categorical variable: low (consisting of those with primary, secondary high school or lower vocational education), middle (consisting of those with secondary vocational education) and high education level (consisting of those with university education).

\subsection{Statistical analyses}

The sample characteristics and Pearson's correlations between all measures were calculated. The total scale score of the DTEDS was highly correlated with the two subscales (eating subscale and general subscale) score ( $r=0.82-0.91)$ and for simplicity only analyses using the general scores from this questionnaire are reported.

Our primary analysis tested the hypothesis that depression has an effect on BMI through dichotomous thinking and emotional eating. A two-mediator model was used to predict the direct and indirect effects of the mediators on the depression-BMI relationship.

Fig. 1 (adapted from Preacher and Hayes (2008)) presents an illustration of a two-mediator design. With this model we investigated the total indirect effects of the selected mediators in the depression-BMI relationship. We analyzed the specific indirect effects - that is, the unique abilities of each mediator to account for the effect of depression on BMI, controlling for the effects of the second mediator.

In order to ensure that the normality of the sampling distribution is not violated, bootstrapped indirect effects and their confidence intervals were calculated.

Age and education level were included as covariates in the analysis. Mediation was considered to have occurred if the $95 \%$ bias corrected confidence intervals (CIs) for the effects generated did not contain zero. All analyses were performed using SPSS v.21 (Corp., Released 2012.) and Stata v.13 (StataCorp., 2013).

\section{Results}

\subsection{Descriptives}

The mean BMI, depression, emotional eating and dichotomous thinking of the participants are presented in Table 1. Participants $(\mathrm{n}=205)$ aged $19-58$ years $(\mathrm{M}=36.77, \mathrm{SD}=11.75)$ with mean $\operatorname{BMI}(30.15, \mathrm{SD}=6.98)$ falling into the obese range and mean emotional eating score $(2.84, \mathrm{SD}=0.95)$ lying above average based on norms for people with obesity (2.3-2.4) (van Strien et al., 1986). In addition, 91\% of the sample was women and $45 \%$ of the sample was classified as highly educated, $53 \%$ as middle educated and $2 \%$ as low educated. The mean score for the dichotomous thinking scale was $22.44(\mathrm{SD}=7.42)$ and for the depression scale $8.33(\mathrm{SD}=8.11)$.

\subsection{Correlations among the assessments of the sample}

Depression was positively correlated with BMI $(\mathrm{r}=0.21, \mathrm{p}=$ $0.005)$, emotional eating $(r=0.38, p<0.001)$ and dichotomous thinking $(r=0.49, p<0.001)$. Dichotomous thinking and emotional eating were positively correlated with BMI $(\mathrm{r}=0.35, \mathrm{p}<0.001$; and $\mathrm{r}=$ $0.45, \mathrm{p}<0.001$ respectively).

\subsection{Mediation effect of dichotomous thinking and emotional eating on the association between depression and BMI}

The total and specific indirect effects of depression on BMI are presented in Table 2 .

The total indirect effect of depression on BMI is $\mathrm{f}=\mathrm{a}_{1} \mathrm{~b}_{1}+\mathrm{a}_{2} \mathrm{~b}_{2}=$ 0.20 , which leads to the rejection of the null hypothesis that the total indirect effect is zero ( $\mathrm{p}=0.0001$ ). This means that dichotomous thinking and emotional eating may mediate the relationship between depression and BMI. After including both mediators in the model, the direct effect of

Table 1

Characteristics of the measures of the sample.

\begin{tabular}{lll}
\hline & \multicolumn{2}{c}{ Participants $(\mathrm{n}=205)$} \\
\cline { 2 - 3 } & Mean & SD \\
\hline BMI (18.5-54.9) & 30.15 & 6.98 \\
Age (19-58) & 36.77 & 11.75 \\
Beck Depression Inventory-II (BDI-II) & & \\
Depression (0-33) & 8.33 & 8.11 \\
Dutch Eating Behavior Questionnaire (DEBQ) & \\
Emotional eating (1-4.85) & 2.84 & 0.95 \\
Dichotomous thinking in Eating Disorders scale (DTEDS) & \\
General score (11-43) & 22.44 & 7.42 \\
Education level & $\mathrm{n}$ & $\%$ \\
\hline Low & 5 & 2.44 \\
Middle & 108 & 44.68 \\
High & 92 & \\
\hline
\end{tabular}

SD; standard deviation, n; number of participants. 
Table 2

Mediation effect of dichotomous thinking and emotional eating on the association between depression and BMI.

\begin{tabular}{|c|c|c|c|c|c|}
\hline & \multirow{3}{*}{$\begin{array}{l}\text { Point } \\
\text { estimate }\end{array}$} & \multirow{2}{*}{\multicolumn{2}{|c|}{$\begin{array}{l}\text { Product of } \\
\text { coefficients }\end{array}$}} & \multirow{2}{*}{\multicolumn{2}{|c|}{$\frac{\text { Bootstrapping }}{\text { BC 95\% CI }}$}} \\
\hline & & & & & \\
\hline & & SE & $\mathrm{Z}$ & Lower & Upper \\
\hline \multicolumn{6}{|l|}{ Indirect effects } \\
\hline Dichotomous thinking & 0.08 & 0.03 & $2.54^{* *}$ & 0.01 & 0.17 \\
\hline Emotional eating & 0.12 & 0.03 & $3.92^{* * *}$ & 0.06 & 0.19 \\
\hline Total & 0.20 & 0.04 & $4.94^{* * *}$ & 0.12 & 0.29 \\
\hline \multicolumn{6}{|l|}{ Contrast } \\
\hline $\begin{array}{l}\text { Dichotomous thinking vs. } \\
\text { emotional eating }\end{array}$ & -0.04 & 0.05 & -0.77 & -0.17 & 0.08 \\
\hline \multicolumn{6}{|c|}{$\begin{array}{l}\text { Note: SE, standard error; BC, bias corrected; } 1000 \text { bootstrap samples. } \\
\text { Analysis adjusted for age and education. } \\
{ }_{* *} \quad \mathrm{p}<0.01 \text {. }\end{array}$} \\
\hline \multicolumn{6}{|l|}{$* * * \quad \mathrm{p}<0.001$} \\
\hline
\end{tabular}

depression on BMI became non-significant $(b=0.02, p=0.73$ ). Similar were the results when each mediator was separately included in the model. The direct effect of depression on BMI was non-significant neither when only dichotomous thinking $(b=0.04, p=0.54)$ was included in the model nor when only emotional eating $(b=0.03, p=0.54)$ was included in the model.

The specific indirect effect through dichotomous thinking is $\mathrm{a}_{1} \mathrm{~b}_{1}=$ $0.08(0.01-0.17)$ and through emotional eating is $\mathrm{a}_{2} \mathrm{~b}_{2}=0.12(0.06-$ 0.19). The standard errors (SEs) and the critical ratios for these effects are reported in Table 2. Of the mediators examined, both dichotomous thinking $(Z=2.54, p=0.01)$ and emotional eating $(Z=3.92, p=$ 0.0002 ) were important mediators.

Even though the specific indirect effect of emotional eating is larger compared to dichotomous thinking, the investigation of the contrast (fcon $a_{1} b_{1}-a_{2} b_{2}$ ) between the two suggested that there is no difference in their role as mediators in the depression-BMI relationship (zero is contained in the confidence interval of the pairwise contrast).

\section{Discussion}

The results of this study show that the relationship between depression and BMI may be mediated by both dichotomous thinking and emotional eating. The directions of the total and indirect (mediated) effect paths are consistent with the interpretation that higher depression leads to higher emotional eating and dichotomous thinking, which in turn leads to increased BMI. The indirect effect of emotional eating was larger than the effect of dichotomous thinking on the relationship. However, when the two mediators were compared in terms of their distinct effect on BMI, there was no difference, suggesting that each of the two mediators exerts a unique effect on the relationship.

Dichotomous thinking is characterized by extreme patterns of thoughts. The results of our study showed that dichotomous thinking may mediate the relationship between depression and obesity. This may suggest that negative emotions may lead to negative thoughts regarding overeating and thus leading to increased BMI.

Previous research has supported the role of dichotomous thinking in predicting weight regain (Byrne, Cooper, \& Fairburn, 2004) (Byrne et al., 2008 ) by predisposing individuals to abandon any dietary restriction, especially in the presence of depressive symptoms. On the other hand, a dichotomous approach to caloric restriction may promote weight loss, by facilitating strict adherence to a predefined eating pattern (Airaksinen, Larsson, Lundberg, \& Forsell, 2004). Consistent with the implication of dichotomous thinking in weight regain, are our results, which suggest that an "all-or-nothing" attitude may increase overweight in people with depressive symptoms. Similarly, this "all-ornothing" attitude towards eating and weight management may lead to binge eating or overeating and a failure to lose weight (Fairburn et al., 2003). It is plausible to accept.
In addition, we found that emotional eating mediates the depression-BMI relationship. Previous research on eating disorders, with a focus on binge-eating disorder, has shown that negative emotional states often precede uncontrolled eating episodes (Greeno, Wing, \& Shiffman, 2000) and depressive symptoms prospectively predict the development of eating disorders (Measelle, Stice, \& Hogansen, 2006). Higher depressive symptoms predicted weight gain and weight loss in a 3-year follow-up of middle-aged men and women from the general population (Haukkala, Uutela, \& Salomaa, 2001). Moreover, a longitudinal study on the role of emotional eating on the association between depression and weight gain showed that emotional eating can act as a mediating factor in this association (T. van Strien et al., 2016).

Consistent with this explanation are the results of a study (Konttinen, Mannisto, Sarlio-Lahteenkorva, Silventoinen, \& Haukkala, 2010), which showed that emotional eating accounted for the positive associations between depressive symptoms and the consumption of energy-dense foods. It is still not very clear why some people have a tendency to eat in response to negative emotions, but among the mechanisms that have been proposed include the inability to distinguish hunger from other aversive internal states (Abramson \& Wunderlich, 1972), the use of eating as an affect regulation strategy (Abramson \& Wunderlich, 1972) and overeating as a consequence of escaping from self-awareness (Heatherton \& Baumeister, 1991).

Bongers and Jansen (2015) showed that participants, in an appetitive conditioning experiment, learned to expect and desire high palatable food (chocolate), when being in an (induced) negative emotional state. Interestingly, in the same study, after food intake, negative emotions were rated as less unpleasant by emotional eaters. This finding supports the aforementioned theories of affect regulation and the escape theory, which suggest that food intake can improve mood, either by reducing negative emotions (affect regulation) or by enhancing a distraction from self-awareness (escape theory) (Bongers \& Jansen, 2015).

However, recent studies suggest (Bongers, Jansen, Havermans, Roefs, \& Nederkoorn, 2013) that positive emotions can also cause overeating. The exact mechanisms though, explaining these associations still need to be identified.

By using a mediational model design, our study supports the idea that emotional eating and dichotomous thinking could be part of the mechanisms via which depressive symptoms are related to increased BMI. Considering this, weight-control strategies that mainly focus on energy-restricted diets, without addressing emotional eating and dichotomous thinking may be less effective. Interventions should rather focus on eating behaviors and attitudes, by enhancing eating for physical rather than emotional reasons and by reducing dichotomous thinking, in order to promote a better regulation of caloric intake to improve healthy weight.

In essence, teaching emotional eaters emotion regulation skills could result in a decrease of emotional eating and weight gain (Roosen, Safer, Adler, Cebolla, \& van Strien, 2012). Although the neurobiology of emotional eating is not completely understood, Van Strien and colleagues (T. van Strien, Roelofs, \& de Weerth, 2013) have shown that high emotional eaters consumed the most food when they had high cortisol response to stress as outcome of a blunted reactivity of the hypothalamus-pituitary-adrenal (HPA) axis. The same physiological state is found in patients suffering from atypical depression and it would therefore worth exploring whether such intervention could be also applied to reduce emotional eating and further the incidence of obesity. On a cognitive level, mindfulness training has shown to reduce identification with thoughts about food, thereby interrupting dysfunctional thinking patterns (Albers, 2011) leading to more controlled food intake.

One of the limitations of this study is the cross-sectional design, which precludes conclusion about causality or its direction. Because of the bidirectional association of depression and BMI we tested the mediational model assuming that BMI precedes depression. Our results suggested that emotional eating and dichotomous thinking could as well 
mediate the association between BMI and depression. Experimental studies are needed to establish causality. For example, the association between depression and increased BMI observed in this study could be explained by either depression leading to increased BMI or increased BMI leading to depression-there is evidence for both (Luppino et al., 2010).

Another limitation was the reliance on self-reports which could have an influence on the study findings. In addition, females and people with high education level were overrepresented in the sample.

\section{Conclusions}

The present study adds to the existing scientific literature related to the role of dysfunctional cognitive styles and emotions on eating behavior, and particularly to some factors that may impede or enhance people's ability to control their eating. While outcomes of previous studies on dichotomous thinking and emotional eating can be generalized only to people with obesity or people with eating disorders, our findings have wider implications concerning people with normal weight as well.

In summary our results suggest that dichotomous thinking and emotional eating may have an adverse outcome on the relationship between depression and BMI. Dysfunctional thinking and emotions should be limited since they can hinder people's ability for weight control.

\section{References}

Abramson, E. E., \& Wunderlich, R. A. (1972). Anxiety, fear and eating: A test of the psychosomatic concept of obesity. Journal of Abnormal Psychology, 79(3), 317-321.

Airaksinen, E., Larsson, M., Lundberg, I., \& Forsell, Y. (2004). Cognitive functions in depressive disorders: Evidence from a population-based study. Psychological Medicine, 34(1), 83-91.

Albers, S. (2011). Using mindful eating to treat food restriction. A case study. Eating Disorders, 19, 97-107.

Alberts, H. J., Thewissen, R., \& Raes, L. (2012). Dealing with problematic eating behaviour. The effects of a mindfulness-based intervention on eating behaviour, food cravings, dichotomous thinking and body image concern. Appetite, 58(3), 847-851. http://dx doi.org/10.1016/j.appet.2012.01.009.

Baumeister, H., \& Harter, M. (2007). Mental disorders in patients with obesity in comparison with healthy probands. International Journal of Obesity, 31(7), 1155-1164. http:// dx.doi.org/10.1038/sj.ijo.0803556.

Beck, A. T. (2008). The evolution of the cognitive model of depression and its neurobiological correlates. The American Journal of Psychiatry, 165(8), 969-977. http://dx.doi. org/10.1176/appi.ajp.2008.08050721.

Blaine, B. (2008). Does depression cause obesity? A meta-analysis of longitudinal studies of depression and weight control. Journal of Health Psychology, 13, 1190-1197.

Bongers, P., \& Jansen, A. (2015). Emotional eating and Pavlovian learning: Evidence for conditioned appetitive responding to negative emotional states. Cognition $\mathcal{E}$ Emotion, 1-14. http://dx.doi.org/10.1080/02699931.2015.1108903.

Bongers, P., Jansen, A., Havermans, R., Roefs, A., \& Nederkoorn, C. (2013). Happy eating: The underestimated role of overeating in a positive mood. Appetite, 67, 74-80. http://dx.doi.org/10.1016/j.appet.2013.03.017.

Byrne, S. M., Allen, K. L., Dove, E. R., Watt, F. J. \& Nathan, P. R. (2008). The reliability and validity of the dichotomous thinking in eating disorders scale. Eating Behaviors, 9(2), 154-162. http://dx.doi.org/10.1016/j.eatbeh.2007.07.002.

Byrne, S. M., Cooper, Z., \& Fairburn, C. G. (2004). Psychological predictors of weight regain in obesity. Behaviour Research and Therapy, 42(11), 1341-1356. http://dx.doi.org/10. 1016/j.brat.2003.09.004

Carpenter, K. M., Hasin, D. S., Allison, D. B., \& Faith, M. S. (2000). Relationships between obesity and DSM-IV major depressive disorder, suicide ideation, and suicide attempts: Results from a general population study. American Journal of Public Health $90(2), 251-257$

Corp., I. (Released (2012). IBM SPSS Statistics for Windows. Armonk, NY: IBM Corp.

de Wit, L., Luppino, F., van Straten, A., Penninx, B., Zitman, F., \& Cuijpers, P. (2010). Depression and obesity: A meta-analysis of community-based studies. Psychiatry Research, 178(2), 230-235. http://dx.doi.org/10.1016/j.psychres.2009.04.015.

Dove, E. R., Byrne, S. M., \& Bruce, N. W. (2009). Effect of dichotomous thinking on the as sociation of depression with BMI and weight change among obese females. Behaviou Research and Therapy, 47(6), 529-534. http://dx.doi.org/10.1016/j.brat.2009.02.013.

Fairburn, C. G., Cooper, Z., \& Shafran, R. (2003). Cognitive behaviour therapy for eating disorders: A "transdiagnostic" theory and treatment. Behaviour Research an Therapy, 41(5), 509-528.

Geliebter, A., \& Aversa, A. (2003a). Emotional eating in overweight, normal weight, and underweight individuals. Eating Behaviors, 3(4), 341-347.

Geliebter, A., \& Aversa, A. (2003b). Emotional eating in overweight, normal weight, and underweight individuals. Eating Behaviors, 3(4), 341-347.

Greeno, C. G., Wing, R. R., \& Shiffman, S. (2000). Binge antecedents in obese women with and without binge eating disorder. Journal of Consulting and Clinical Psychology, 68(1), 95-102.
Haukkala, A., Uutela, A., \& Salomaa, V. (2001). Depressive symptoms, cynical hostility, and weight change: A 3-year follow-up among middle-aged men and women. International Journal of Behavioral Medicine, 8, 116-133.

Heatherton, T. F., \& Baumeister, R. F. (1991). Binge eating as escape from self-awareness. Psychological Bulletin, 110(1), 86-108.

Heo, M., Pietrobelli, A., Fontaine, K. R., Sirey, J. A., \& Faith, M. S. (2006). Depressive mood and obesity in US adults: Comparison and moderation by sex, age, and race. International Journal of Obesity, 30(3), 513-519. http://dx.doi.org/10.1038/sj.ijo. 0803122.

Herva, A., Laitinen, J., Miettunen, J., Veijola, J., Karvonen, J. T., Laksy, K., \& Joukamaa, M. (2006). Obesity and depression: Results from the longitudinal Northern Finland 1966 Birth Cohort Study. International Journal of Obesity, 30(3), 520-527. http://dx. doi.org/10.1038/sj.ijo.0803174.

Kontinnen, H., Silverntoinen, K., Sarlio-Lahteenkorva, S., Mannisto, S., \& Haukkala, A. (2010). Emotional eating and physical activity self-efficacy as pathways in the association between depressive symptoms and adiposity indicators. American Journal of Clinical Nutrition, 92, 1031-1039.

Konttinen, H., Mannisto, S., Sarlio-Lahteenkorva, S., Silventoinen, K., \& Haukkala, A. (2010). Emotional eating, depressive symptoms and self-reported food consumption. A population-based study. Appetite, 54(3), 473-479. http://dx.doi.org/10.1016/j. appet.2010.01.014.

Kraemer, H. C., Stice, E., Kazdin, A., Offord, D., \& Kupfer, D. (2001). How do risk factors work together? Mediators, moderators, and independent, overlapping, and proxy risk factors. The American Journal of Psychiatry, 158(6), 848-856. http://dx.doi.org/ 10.1176/appi.ajp.158.6.848.

Lethbridge, J., Watson, H. J., Egan, S. J., Street, H., \& Nathan, P. R. (2011). The role of perfectionism, dichotomous thinking, shape and weight overvaluation, and conditional goal setting in eating disorders. Eating Behaviors, 12(3), 200-206. http://dx.doi.org/10. 1016/j.eatbeh.2011.04.003.

Luppino, F. S., de Wit, L. M., Bouvy, P. F., Stijnen, T., Cuijpers, P., Penninx, B. W., \& Zitman, F. G. (2010). Overweight, obesity, and depression: A systematic review and meta-analysis of longitudinal studies. Archives of General Psychiatry, 67(3), 220-229. http://dx. doi.org/10.1001/archgenpsychiatry.2010.2.

Marcus, M., M., Y., Van Ommeren, M., Chisholm, D., \& Saxena, S. (2012). Depression: a global public health concern. World Health Organization paper on depression. (pp. 6-8), 6-8.

Markowitz, S., Friedman, M. A., \& Arent, S. M. (2008). Understanding the relation between obesity and depression: Causal mechanisms and implications for treatment. Clinical Psychology: Science and Practice, 15, 1-20.

Mathers, C. D., \& Loncar, D. (2006). Projections of global mortality and burden of disease from 2002 to 2030. PLoS Medicine, 3(11), e442. http://dx.doi.org/10.1371/journal. pmed.0030442.

McElroy, S. L., Kotwal, R., Malhotra, S., Nelson, E. B., Keck, P. E., \& Nemeroff, C. B. (2004). Are mood disorders and obesity related? A review for the mental health professional. The Journal of Clinical Psychiatry, 65(5), 634-651 (quiz 730).

Measelle, J. R., Stice, E., \& Hogansen, J. M. (2006). Developmental trajectories of co-occurring depressive, eating, antisocial, and substance abuse problems in female adolescents. Journal of Abnormal Psychology, 115(3), 524-538. http://dx.doi.org/10.1037/ 0021-843X.115.3.524.

Murray, C. J., \& Lopez, A. D. (1997). Alternative projections of mortality and disability by cause 1990-2020: Global Burden of Disease Study. Lancet, 349(9064), 1498-1504. http://dx.doi.org/10.1016/S0140-6736(96)07492-2.

Organization, W. H (2013). Obesity and overweight. Retrieved from http://www.who. int/mediacentre/factsheets/fs311/en/

Owens, M. A., v. S., T., \& van Leeuwe, J. F. (2009). Possible pathways between depression, emotional and external eating. A structural equation model. Appetite, 53(2), 245-248.

Ozier, A. D., Kendrick, O. W., Leeper, J. D., Knol, L. L., Perko, M., \& Burnham, J. (2008). Overweight and obesity are associated with emotion- and stress-related eating as measured by the eating and appraisal due to emotions and stress questionnaire. Journal of the American Dietetic Association, 108(1), 49-56. http://dx.doi.org/10.1016/j.jada. 2007.10.011.

Preacher, K. J., \& Hayes, A. F. (2008). Asymptotic and resampling strategies for assessing and comparing indirect effects in multiple mediator models. Behavior Research Methods, 40(3), 879-891.

Roosen, M. A., Safer, D., Adler, S., Cebolla, A., \& van Strien, T. (2012). Group dialectical behavior therapy adapted for obese emotional eaters; a pilot study. Nutrición Hospitalaria, 27(4), 1141-1147. http://dx.doi.org/10.3305/nh.2012. 27.4.5843.

Ross, C. E. (1994). Overweight and depression. Journal of Health and Social Behavior, 35(1), $63-79$.

Scott, K. M., McGee, M. A., Wells, J. E., \& Oakley Browne, M. A. (2008). Obesity and mental disorders in the adult general population. Journal of Psychosomatic Research, 64(1), 97-105. http://dx.doi.org/10.1016/j.jpsychores.2007.09.006.

StataCorp (2013). Stata Statistical Software.

Teasdale, J. D., Scott, J., Moore, R. G., Hayhurst, H., Pope, M., \& Paykel, E. S. (2001). How does cognitive therapy prevent relapse in residual depression? Evidence from a controlled trial. Journal of Consulting and Clinical Psychology, 69(3), 347-357.

van Strien, T., Frijters, J. E. R., Bergers, G. P. A., \& Defares, P. B. (1986). The Dutch Eating Behavior Questionnaire (DEBO) for assessment of restrained, emotional and external eating behavior. International Journal of Eating Disorders, 5, 295-315.

van Strien, T., Konttinen, H., Homberg, J. R., Engels, R. C., \& Winkens, L. H. (2016). Emotional eating as a mediator between depression and weight gain. Appetite, 100, 216-224. http://dx.doi.org/10.1016/j.appet.2016.02.034. 
van Strien, T., Roelofs, K., \& de Weerth, C. (2013). Cortisol reactivity and distress-induced emotional eating. Psychoneuroendocrinology, 38(5), 677-684. http://dx.doi.org/10. 1016/j.psyneuen.2012.08.008.

von Ruesten, A., Steffen, A., Floegel, A., van der A., D., Masala, G., Tjonneland, A., ... Boeing

H. (2011). Trend in obesity prevalence in European adult cohort populations during follow-up since 1996 and their predictions to 2015. PloS One, 6(11), e27455. http:// dx.doi.org/10.1371/journal.pone.0027455.

Williamson, D. A., White, M. A., York-Crowe, E., \& Stewart, T. M. (2004). Cognitive-behavioral theories of eating disorders. Behavior Modification, 28(6), 711-738. http://dx.doi. org/10.1177/0145445503259853. 